\title{
Improving Durian Fruit Production Through Cultivation Technology in Farmer Groups in Yeh Sumbul Village, Jembrana
}

\author{
Ir. Made Sri Yuliartini, M.Si ; Ir. Luh Kartini, M.Si; Dr. Ir. Ni Putu Anom Sulistiawati, M.Si \\ \{yuliartinisri@yahoo.co.id\}
}

Agrotechnology Study Program, Faculty of Agriculture, Warmadewa University

\begin{abstract}
The PKM activity was carried out at the "MELATI" Farmer Group in Yeh Sumbul Village, Mendoyo Sub-district, Jembrana Regency, Bali Province. This village is a plantation area and a center for producing horticultural fruit products, such as durian plants, which is a good business opportunity, with high selling price, due to its delicious taste, sweet fruit flesh, and distinctive aroma. There is a yearly and varying increase in the development of durian plants throughout the Yeh Sumbul village. The plants are in an intercropping system with other types, therefore its maintenance is not focused, with low yields and inability of farmers to familiarize with good cultivation techniques which produces low yield quality and quantity. Therefore, the purpose of this PKM activity is to provide the right and appropriate counseling material on the durian cultivation technology with farmer groups in order to determine the best technique needed to fertilize and prune the durian plants. From this activity, the output target aims at training participants from the farmers group to understand how to cultivate durian plants correctly and appropriately to provide high quality and quantity of yields. The activity is implemented in the form of service, provision of counseling materials, training and assistence in the field. The results showed that farmers understand and are willing to carry out environmental sanitation, determine one year old plants that are planted in the backyard, and use organic and inorganic fertilizers. For old durian plants in garden mixed with other fruits, it is important to clean the surrounding environment, fertilize the area before rain falls due to the hilly terrain, which only relies on rain water. The Kani and Montong durian plants tend to carry out pruning, maintenance, fertilizing and irrigation because the plants are only five years old and are planted on the edge of the garden, and liable to irrigation.
\end{abstract}

Keywords: Durian Plants, Cultivation Technology Input, Farmer Groups

\section{Pendahuluan}

Potensi dan peluang pasar komoditas hortikultura khususnya buah-buahan semakin meningkat seiring dengan meningkatnya permintaan masyarakat terhadap buah-buahan yang 
bermutu tinggi. Buah Durian terkenal dengan rasanya yang lezat dan daging yang legit, selain itu, buah durian juga memiliki aroma yang khas. Banyaknya jenis durian membuat penikmatnya semakin senang berburu buah berduri yang satu ini. Beberapa varietas durian yang menjadi primadona antara lain : buah durian musangking, Durian Bawor, Durian Montong, Durian Petruk, Durian merah dan Durian pelangi. Tanaman buah durian dikenal dengan tanaman musiman dan hanya berbuah di musim-musim tertentu saja (Ali Arwani, 2016). Komoditas tanaman buah durian mempunyai peluang bisnis yang cukup bagus. Buahnya memiliki harga jual yang cukup mahal, selain itu, terkadang masih terasa kurang pasokannya di pasar tradisional maupun supermarket. Berdasarkan survei di Desa Yeh Sumbul, daerah ini mempunyai keanekaragaman tanaman buah yang cukup tinggi dimana tanaman Durian bercampur dengan jenis tanaman lainnya seperti kelapa, manggis, nangka, papaya, pisang serta ada sereh dan lain-lain dalam satu areal kebun yang berbukit. Ketersediaan berbaga jenis tanaman tersebut merupakan kondisi yang baik bagi perkembangan perekonomian dan juga untuk memperoleh keanekaragaman jenis komoditi yang diinginkan, dengan harapan juga membantu kesuburan lahan dengan diterapkannya pola tumpang sari pada sebidang lahan; akan tetapi petani tidak fokus dalam pemeliharaan tanaman durian tersebut. Sehingga hasil buah durian yang didapat rendah dan tidak bermutu. Oleh karena itu perlu usaha untuk memperbaikinya. teknik budidaya melalui peningkatan budidaya secara maksimal, merupakan salah satu alternatif . Teknik budidaya lebih pada pemupukan, pemangkasan, sanitasi lingkungan, pengendalian hama dan penyakit.

Pelaksanaan Program Kemitraan Masyarakat (PKM) akan bermitra dengan 1 (satu) kelompok tani yang memiliki kemauan kuat untuk maju dan mengelola usahanya dengan baik yaitu kelompok tani "MELATI" yang terdiri dari 5 orang anggota dan diketuai oleh I Nengah Tika. Berdasarkan hasil observasi dilapang dapat diperoleh informasi permasalahan yang dihadapi mitra yaitu : 1) Pengembangan tanaman durian di seluruh wilayah desa dan kecamatan sangat bervariasi dan meningkat dari tahun ke tahun. (2) Tanaman durian berada dalam sistem tanaman tumpang sari dengan tanaman jenis lainnya sehingga pemeliharaan tidak terfokus dan hasil tanaman durian yang didapat rendah walaupun ada diversitas tanaman lain sebagai penunjang hasil. (3) Beberapa Tanaman Durian sudah berumur tahunan dan sudah diperlukan peremajaan . (4) Petani belum begitu paham dengan teknik budidaya yang benar dan tepat sehingga kualitas dan kuantitas hasil masih rendah terutama pemupukan, pemangkasan serta sanitasi lingkungan

Secara umum petani tidak begitu memelihara tanaman secara khusus dan hanya dibiarkan begitu saja terutama yang dikebun dengan medan bergelombang serta bercampur tanaman buah lainnya dan hanya mengandalkan musim serta alam tetapi peremajaan pada petani ada yang menanam di pekarangan tersendiri dan itupun masih dibiarkan tanpa pemupukan serta pemangkasan sehingga tanaman belum mampu memberikan hasil yang maksimal . 


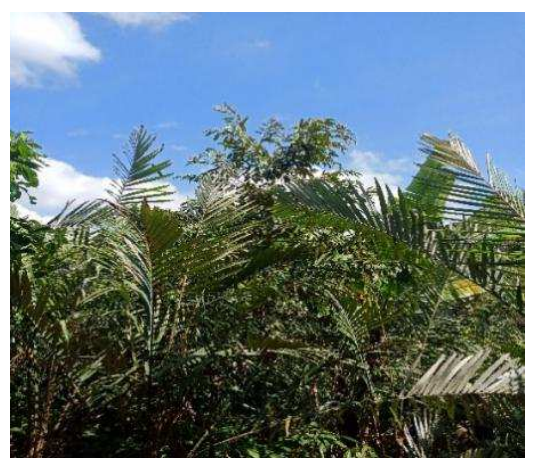

Tujuan Kegiatan PKM

Penyuluhan dan praktek langsung di lapangan memberikan dampak pada usahataninya serta menambah pengatahuan petani tentang pemahaman teknologi budidaya tanaman durian yang benar dan tepat sehingga nantinya dapat meningkatkan kuantitas dan kualitas hasil tanaman durian, baik yang dalam sistem tumpang sari maupun yang di tanam secara monokultur. Hal ini nantinya dapat meningkatkan pendapatan petani kelompok Tani Melati serta dapat menularkan kepada petani lainnya sehingga memiliki kemampuan manajemen usaha yang lebih baik.

Metode yang akan digunakan untuk memudahkan serta melancarkan dalam penyerapan materi pada PKM ini, maka dilakukan :

1. Metode wawancara dan diskusi untuk mengetahui masalah yang dihadapi oleh mitra kerja

2. Motode penyuluhan melalui tatap muka serta diskusi secara langsung, agar petani mitra mendapatkan ilmu pengetahuan mengenai penerapan teknologi budidaya yang baik dan tepat serta berkelanjutan sehingga nantinya dapat meningkatkan kualitas dan kuantitas hasil buah durian . Materi penyuluhan berupa liflet .

3. Praktek langsung di lapangan seperti pemupukan dan pemangkasan serta pembersihan lingkungan.

Dengan mencermati analisis situasi dan permasalahan yang dihadapi oleh Kelompok Tani Melati Desa Yeh Sumbul, Kecamatan Mendoyo, Kabupaten Jemberana, maka ditawarkan penyelesaian dalam rangkaian Pengabdian Kemitraan Masyarakat (PKM) adalah :

1. Kuantitas dan kualitas hasil tanaman durian masih rendah. Sentuhan atau input teknologi budidaya berupa kegiatan penyuluhan dan pelatihan, melalui penyusunan paket teknologi budidaya yang tepat.

2. Pengenalan dan mempraktekan di lapangan pada tanaman durian sebagai pedoman bagi kelompok tani mitra dalam melakukan usahataninya sehingga akan terjadi peningkatan pengetahuan bagi petani tanaman durian untuk mengembangkan usaha agribisnisnya, yang pada akhirnya dapat meningkatkan pendapatan petani.

3. Peningkatan Kuantitas maupun kualitas hasil dengan penerapan teknik budidaya yang didapatkan , nantinya secara komersial dapat bersaing lebih luas di pasar tradisional maupun swalayan .

4. Kondisi iklim dan penanaman yang bercampur dapat mengurangi hasil tanaman durian. Jadi sanitasi lingkungan, pemangkasan serta pengendalian hama dan penyakit perlu dilakukan secara rutin .

5. Perlu peremajaan dengan bibit baru dari tanaman durian sehingga nantinya hasil yang didapat lebih meningkat sehingga berpengaruh pada peningkatan pendapatan mitra. 
Hasil Kegiatan Pengabdian PKM:

dengan memberi penyuluhan, pelatihan , praktek langsung serta pendampingan sehingga pertumbuhan dan perkembangan tanaman durian semakin baik dan berpengaruh terhadap hasil yang tinggi. Ini telah dilakukan melalui pemberian materi penyuluhan, pelatihan dan pendampingan di lapang. Telah didapat bahwa petani paham dan mau melakukan sanitasi lingkungan, melakukan pemangkasan awal untuk pembentukan tanaman yang ditanam di pekarangan belakang rumah dan baru berumur satu tahun serta melakukan pemupukan dengan menggunakan pupuk organik serta pupuk anorganik .

Pada tanaman durian di kebun yang sudah berumur yang bercampur dengan tanaman buah lainnya, lebih dilakukan pada pembersihan lingkungan sekitar tanaman, pemupukan menjelang turunnya hujan karena medannya berbukit jadi pengairan hanya mengandalkan air hujan . Untuk tanaman durian Kani, Montong dilakukan pemangkasan pemeliharaan serta pemupukan dan pengairan karena tanaman baru berumur lima tahun dan ditanam di pinggiran kebun, jadi masih terjangkau untuk pengairannya. Pupuk Organik yang digunakan adalah pupuk organik dari limbah kulit durian yang dibuat oleh kelompok tani Melati saat Pengabdian hibah tahun 2018 tapi belum cukup banyak dan dicampur dengan pupuk organik dari kelompok tani ternak setempat, sedangkan pupuk anorganik adalah pupuk NPK Mutiara. Pada pengabdian kita memberikan bibit tanaman durian jenis Montong, Kani dan Musangking untuk peremajaan dan ditanam di pekarangan belakang rumah sehingga nantinya lebih mudah dalam pendampingan lanjutan.

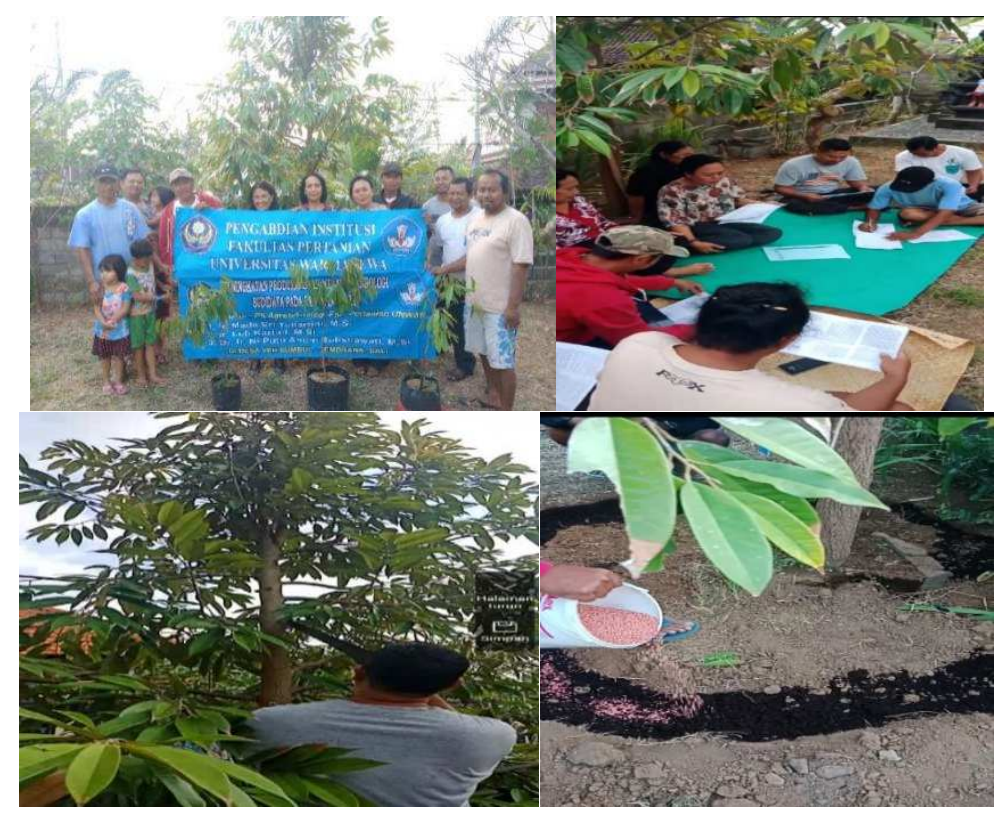




\section{Kesimpulan}

Dari hasil pengabdian kepada kelompok tani "MELATI" ; petani sudah mengerti dan paham dalam meningkatkan kemampuan teknik budidaya tanaman durian secara tepat dan benar sehingga meningkatkan pertumbuhan dan perkembangan yang nantinya dapat meningkatkan hasil tanaman durian baik dari segi kualitas maupun kuantitas , perlu dilakukan peremajaan dengan penanaman varietas durian unggul dengan memanfaatkan pekarangan di belakang rumah sehingga penerapan teknik budidaya dapat maksimal. Pengabdian peningkatan hasil tanaman durian dengan melalui teknologi budidaya yang tepat dan benar dapat menjadi sumber peningkatan pendapatan masyarakat petani sehingga perlu disosialisasikan pada kelompok tani yang lain.

\section{References}

[1] Ali Arwani. 2016. 9 Tips Mudah Cara Budidaya Tanaman Buah Durian Agar Mampu Tumbuh Optimal, Cepat Berbuah dan Berproduksi Tinggi.

[2] Al Faeyza Khair Jauhari . 2016. Teknik Budidaya Durian agar cepat berbuah

[3] Direktorat Budidaya Tanaman Buah, Direktorat Jenderal Hortikultura, Depatemen Pertanian, 2006. Standard Operating Procedure (SOP) Durian Sitokong, Kabupaten Kutai Kertanegara

[4] Direktorat Budidaya Tanaman Buah, Direktorat Jenderal Hortikultura, Kementerian Pertanian, 2010. Standard Operating Procedure (SOP) Durian Kajang, Kabupaten Tanggamus

[5] Jumali,SP. 2017. Pedoman Budidaya Tanaman Durian. Penyuluh Kabupaten Sleman.

[6] Kecamatan Mendoyo dalam angka. 2017. Desa Yeh Sumbul , Kecamatan Mendoyo, Kabupaten Jembrana-Provinsi Bali.

[7] Kantor Deputi Menegristek Bidang Pendayagunaan dan Pemasyarakatan Ilmu Pengetahuan dan Teknologi. 2000. Tentang Budidaya Pertanian Durian (Bombaceaesp).

[8] Zulkarnain, H. 2009. Dasar-dasar Hortikultura. Penerbit PT. Bumi Aksara-Jakarta 